\title{
Contribuições de recursos pedagógicos sobre câncer de pele para alfabetização científica no ensino fundamental
}

Patricia Marega

pmarega2010@hotmail.com orcid.org/0000-0003-4018-5663 Universidade Federal de Santa Maria, Santa Maria, Rio Grande do Sul, Brasil

Marcelo Leite da Veiga marcelolveiga@gmail.com orcid.org/0000-0002-9303-3324 Universidade Federal de Santa Maria, Santa Maria, Rio Grande do Sul, Brasil

Maria Rosa Chitolina mariachitolina@gmail.com Universidade Federal de Santa Santa Maria, Rio Grande do Sul, Brasil

\begin{abstract}
RESUMO
De acordo com o Instituto Nacional do Câncer (INCA, 2018), crianças se expõem anualmente ao sol três vezes mais que adultos. Pesquisas indicam que a infância é uma fase particularmente vulnerável aos efeitos nocivos do sol e a exposição cumulativa e excessiva a ele durante os primeiros 10 a 20 anos de vida aumenta muito o risco de câncer de pele na fase adulta ou velhice. Diante disso, este estudo avaliou as contribuições do uso de recursos pedagógicos lúdico-interativos abrangendo o tema câncer de pele para a promoção da Alfabetização Científica de 184 alunos do 3ㅇa ao 9 ano do Ensino Fundamental de duas escolas públicas do campo. Trata-se de uma pesquisa qualitativa do tipo estudo de casos múltiplos. Foi realizada uma oficina, onde os alunos receberam uma cartilha, um folder e um flyer que abordavam o tema câncer de pele, com os quais interagiram e puderam leválos para casa. Os instrumentos de coleta de dados foram: diário de campo, questionário e composição de um texto. O tratamento dos dados foi baseado em estatística descritiva e análise de conteúdo. Os resultados demonstraram que os recursos pedagógicos favoreceram a organização, apropriação e domínio de conceitos científicos básicos a respeito das causas, prevenção e identificação do câncer de pele. Também pôde-se evidenciar diversos indicadores de alfabetização científica, bem como a construção de sentido e significado, habilitando o aluno para agir e escolher com autonomia, fundamentado por conhecimentos científicos. Dessa forma, espera-se que os estudantes se tornem agentes críticos e cidadãos autônomos, capazes de relacionar aprendizagem e vida diária, intervindo no ambiente em que estão inseridos.
\end{abstract}

PALAVRAS-CHAVE: Alfabetização Científica. Ensino Fundamental. Recursos Pedagógicos. Câncer de Pele. 


\section{INTRODUÇÃO}

Segundo a Sociedade Brasileira de Dermatologia - SBD (2018), o câncer de pele responde por $33 \%$ de todos os diagnósticos de câncer no Brasil, sendo que o Instituto Nacional do Câncer (INCA) registra a cada ano, cerca de 180 mil novos casos.

Para cada ano do biênio 2018-2019 no Brasil, estima-se 85.170 novos casos entre homens e 80.410 novos casos entre mulheres de câncer de pele não melanoma (CPNM). Quanto ao melanoma (CPM), sua letalidade é elevada, porém sua incidência é baixa (2.920 casos novos em homens e 3.340 casos novos em mulheres). As maiores taxas estimadas em homens e mulheres encontram-se na Região Sul (INCA, 2018).

A exposição excessiva ao sol é o principal fator de risco para o surgimento de câncer de pele, que se descoberto em fase tardia pode levar a deformidades físicas ou à morte (ZINK, 2014; PEREIRA, 2017; INCA, 2018, SBD, 2018). De acordo com o Instituto Nacional do Câncer (INCA, 2018), crianças se expõem anualmente ao sol três vezes mais que adultos. Pesquisas indicam que a infância é uma fase particularmente vulnerável aos efeitos nocivos do sol e a exposição cumulativa e excessiva a ele durante os primeiros 10 a 20 anos de vida aumenta muito o risco de câncer de pele na fase adulta ou velhice (CRIADO; MELO; OLIVEIRA, 2012; CORRÊA; PIRES, 2013; INCA, 2018).

Considerando que o câncer de pele é um problema de saúde pública, mas de controle factível pela prevenção, primária - proteção contra a exposição excessiva à luz solar - e secundária, realizando diagnóstico precoce e tratamento oportuno (DIEPGEN; MAHLER, 2002), se faz necessário reconhecer a importância de alfabetizar cientificamente as crianças e adolescentes sobre as causas, os meios de prevenção e diagnóstico precoce dessa patologia.

Segundo Salla (2015), constatando-se que uma das principais causas de incidência das patologias evitáveis e controláveis é justamente a falta de conhecimento científico a respeito dos fatores patogênicos das mesmas, a Alfabetização Científica (AC) instrumentaliza o indivíduo para agir no sentido da prevenção e controle dessas morbidades.

De acordo com Sasseron e Carvalho (2011), a AC promove no indivíduo a capacidade de organizar seu pensamento de maneira lógica, e permite a construção de uma consciência mais crítica em relação ao mundo que o cerca. Segundo as autoras, a AC almeja a formação cidadã dos estudantes para o domínio e uso dos conhecimentos científicos e seus desdobramentos nas mais diferentes esferas de sua vida (SASSERON; CARVALHO, 2011).

Delizoicov e Lorenzetti (2001) ressaltam que o objetivo primeiro da AC não é formar futuros cientistas, embora por meio dela eles possam surgir, mas sim ensinar de forma a sensibilizar o sujeito para que ele possa desenvolver uma compreensão do mundo, das suas ações para com o meio em que vive, compreendendo e aplicando este conhecimento. Segundo os autores, o processo de $A C$ deve iniciar nas primeiras séries da escolarização, permitindo que os alunos participem ativamente no processo ensino-aprendizagem debatendo problemas que afligem sua realidade (DELIZOICOV; LORENZETTI, 2001). 
Para tanto, Amador et al. (2018) entendem que os estudantes do EF têm certas dificuldades em aprender ciências da natureza e um dos principais motivos que levam a este problema é a metodologia utilizada pelo professor ao abordar os conteúdos em sala de aula. Segundo os autores, há a necessidade dos professores proporem novas alternativas didáticas para atrair o interesse dos educandos e buscarem contextualizar o ensino com as problemáticas locais. Neste sentido, Costa e Batista (2017) ressaltam a importância do uso de recursos pedagógicos para compreensão dos conteúdos das ciências.

Massara, Scholte e Enk (2008) salientam que a utilização de material lúdico e interativo para informar, promover e estimular o debate acerca de um determinado tema possibilita a deflagração de um processo cognitivo questionador, favorecendo a reflexão e a aquisição do conhecimento.

Conforme a Base Nacional Comum Curricular (BNCC) (BRASIL, 2018):

Não basta que os conhecimentos científicos sejam apresentados aos alunos.
É preciso oferecer oportunidades para que eles, de fato, envolvam-se em
processos de aprendizagem nos quais possam vivenciar momentos de
investigação que Ihes possibilitem exercitar e ampliar sua curiosidade,
aperfeiçoar sua capacidade de observação, de raciocínio lógico e de criação,
desenvolver posturas mais colaborativas e sistematizar suas primeiras
explicações sobre o mundo natural e tecnológico, e sobre seu corpo, sua
saúde e seu bem-estar (BRASIL, 2018, p. 329).

Desse modo, faz-se necessário propor alternativas a educação em Ciências que proporcionem aos alunos de Ensino Fundamental a apropriação de conhecimentos científicos a respeito das causas, desenvolvimento, prevenção e diagnóstico precoce do câncer de pele, instrumentalizando-os cientificamente para evitá-lo e identificá-lo, contribuindo assim para a educação em saúde e melhoria da qualidade de vida dos estudantes e da comunidade escolar.

Diante do exposto, esta pesquisa pretende verificar as contribuições do uso de recursos pedagógicos de caráter lúdico-interativo contemplando o tema câncer de pele para a promoção da alfabetização científica de alunos do 30 ao 9 음 anos do Ensino Fundamental.

\section{METODOLOGIA}

Trata-se de uma pesquisa qualitativa, segundo o proposto por Minayo (2007), de caráter investigativo e exploratório do tipo estudo de casos múltiplos, de acordo ao conceito apresentado por Yin (2005).

No primeiro momento foi apresentado o projeto à direção das escolas a fim de se obter autorização para a realização da pesquisa. Após agendamento prévio, deu-se início ao trabalho de campo envolvendo 184 estudantes do 3ㅇ ao 9anos do Ensino Fundamental de duas escolas públicas do campo localizadas nas cidades de Silveira Martins/RS e São João do Polêsine - Vale Vêneto/RS, Brasil, denominadas de Escola 1 (E1) e Escola 2 (E2), respectivamente. Considerando que as escolas escolhidas estão localizadas em uma região onde a economia gira em torno da agricultura, com predomínio da produção de arroz, milho e feijão, ocupações que estão associadas à grande exposição solar diária, a presente pesquisa tem a intenção de colaborar também com a comunidade escolar. 
A idade dos participantes variou entre 8 e 14 anos. Todos os alunos participaram da intervenção, mas a coleta de dados foi realizada apenas com os alunos que assentiram participar da pesquisa através da assinatura do Temo de Assentimento e cujos pais e/ou responsáveis assinaram o Termo de Consentimento Livre e Esclarecido, garantindo o sigilo das informações e o anonimato. O projeto de pesquisa foi aprovado pelo Comitê de Pesquisa e Ética da Universidade Federal de Santa Maria, sob o parecer número 2.434.396, CAAE: 79 640017.4.0000.5346.

A distribuição do número de alunos nos anos iniciais e finais da E1 e da E2 está representada na figura 1. Para análise dos resultados, foram agrupados os anos iniciais (do 3ㅇ ao 5ㅇ) e os anos finais (do 6으 ao 9으) do Ensino Fundamental.

Figura 1 - Frequência de alunos nos anos iniciais e finais das escolas analisadas. Escola 1

(E1): anos iniciais $n=52 /$ finais $n=59$. Escola 2 (E2): anos iniciais $n=33 /$ finais $n=40$

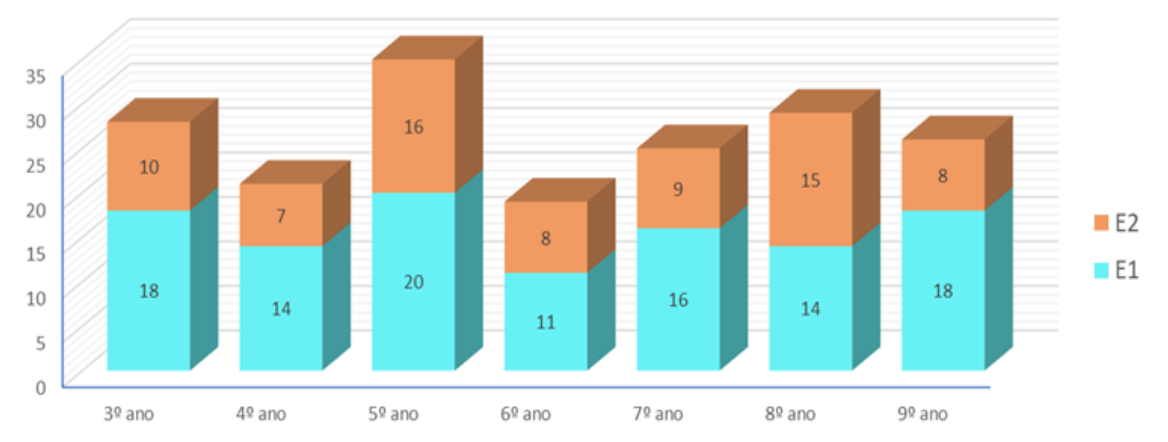

Fonte: Autoria própria (2019).

Como instrumento de coleta de dados utilizou-se o diário de campo, um questionário e a elaboração de um texto. A análise dos dados foi baseada em estatística descritiva (REIS, 1998) com uso de frequências absolutas (n) e relativas (\%) e análise de conteúdo proposta por Bardin (2016). De acordo com Bardin (2016), a análise de conteúdos se constitui como "um conjunto de técnicas de análise de comunicações que utiliza procedimentos sistemáticos e objetivos de descrição do conteúdo das mensagens." (BARDIN, 2016, p.44).

Em cada turma do 3으 ao 9o ano do Ensino Fundamental as ações iniciaram com a realização de uma oficina que tratava sobre o tema câncer de pele. Neste momento os alunos receberam uma cartilha, um folder e um flyer, com os quais interagiram e puderam levar para casa. Os recursos pedagógicos (disponíveis para download no website http://coral.ufsm.br/gaccmps) foram idealizados pelo Grupo de Alfabetização Científica em Ciências Morfológicas para a Promoção da Saúde (GACCMPS) do Departamento de Morfologia do Centro de Ciências da Saúde da Universidade Federal de Santa Maria.

A cartilha paradidática "Melano e Querato na terra do Sol: uma história sobre os efeitos do sol na pele" apresenta as camadas que constituem a pele (epiderme e derme) e as células epidérmicas (melanócito e queratinócito), representadas pelos personagens Melano e Querato, cuja principal função está na proteção da pele contra a ação dos raios ultravioletas do sol. O recurso pedagógico evidencia essa função utilizando linguagem apropriada ao público-alvo, onde o "Melano" produz chapéus (melanina) e distribui para os "Queratos" mais próximos. Essa ação faz analogia ao fato de que a melanina produzida pelos melanócitos é transportada 
para os queratinócitos e se deposita ao redor do núcleo da célula, como se fosse um capuz, protegendo o seu material genético dos efeitos da radiação solar. Também usa ilustrações para demonstrar que o excesso de exposição solar sem a utilização de protetor solar pode provocar alterações morfológicas nas células epidérmicas, fazendo com que as mesmas comecem a se multiplicar rapidamente e de maneira desordenada, levando ao surgimento do câncer de pele. Além disso, orienta sobre a prevenção do câncer de pele e oferece atividades lúdico-interativas como caça-palavras e palavras cruzadas.

O folder "ABCDE do câncer de pele" exibe as características de lesões (manchas) normais da pele e lesões com características sugestivas de tumor de pele do tipo melanoma, tais como: Assimetria (a lesão tem uma metade diferente da outra), Borda irregular (as bordas são indefinidas), Cor (várias cores em uma mesma lesão), Diâmetro (maior que cinco milímetros) e Evolução (a lesão muda rapidamente de forma, cor, tamanho e/ou espessura) (SBD, 2018; INCA, 2018). Também traz atividades complementares (caça-palavras, complete e desenho) a fim de consolidar a apreensão das informações propostas.

O flyer, com mesmo conteúdo do folder, foi entregue para os estudantes com o intuito de que estes disseminassem o assunto apresentado junto à comunidade, agindo como multiplicadores de informações.

Durante a oficina foi feita a exposição dialogada da cartilha e do folder, o que proporcionou a interação entre estudantes, pesquisador e o material utilizado. Essa interação deu abertura ao questionamento e a discussão do tema proposto, instigando a curiosidade e a construção do conhecimento. Para Freire (1987, p. 50), é necessário buscar conteúdo para a educação partindo do princípio da problematização e dialogicidade, contribuindo assim para a apreensão do tema abordado e dos conceitos científicos, o que permitirá a tomada de consciência dos indivíduos envolvidos no processo de ensino aprendizagem, através da percepção da realidade.

A atividade desenvolvida neste primeiro encontro foi realizada na última semana do mês de março de 2017 e totalizou duas horas.

O segundo encontro aconteceu após quinze dias da interação com os recursos pedagógicos. Neste momento foi aplicado um questionário para saber a opinião dos estudantes a respeito do projeto. Dessa forma, foi perguntado sobre a importância de terem participado da pesquisa e da possível divulgação dos conceitos apreendidos para outras pessoas. As respostas foram agrupadas em categorias, sendo que a unidade de registro utilizada para a construção das mesmas foi a ideia central de cada resposta. Para garantir o anonimato na apresentação dos resultados os alunos foram identificados por siglas - A1-E1, 5 -ano (Aluno 1, Escola 1, 5 ano); A23-E2, 60 ano (Aluno 23, Escola 2, 60 ano). Na transcrição das respostas tanto ortografia quanto gramática foram fiéis à escrita dos estudantes.

Oito meses após a realização da oficina retornou-se às escolas a fim de averiguar a possível consolidação de conhecimentos acerca do tema câncer de pele. Para tanto, foi utilizada a metodologia proposta por Oliveira (2009, p. 35), na qual "o uso da escrita como instrumento de aprendizagem realça a construção pessoal do conhecimento." Assim, foi solicitado aos estudantes que escrevessem um pequeno texto ou frase que sintetizasse seu conhecimento sobre o assunto 
apresentado na oficina. A análise dos textos foi feita da mesma forma que a utilizada para o questionário, tendo como referencial os indicadores da alfabetização científica propostos por Sasseron e Carvalho (2008), visto que a participação dos alunos em sala que denotam situações de aprendizagem em Ciências são denominados indicadores de alfabetização científica.

\section{RESULTADOS E DISCUSSÃO DA OFICINA}

Durante a realização da oficina, os alunos dos anos iniciais foram convidados a ler em voz alta cada página da cartilha conjuntamente com a pesquisadora, o que propiciou o envolvimento e atenção dos mesmos durante a apresentação e discussão do recurso pedagógico. Assim, todos se mostraram participativos e interessados, questionando sobre o assunto abordado ou relatando histórias e situações familiares inseridas no contexto proposto.

Dessa forma, quando foi explicado sobre as camadas que constituem a pele a derme (vascular) e a epiderme (avascular), um aluno do 4 o ano questionou "por que quando cortamos o dedo com uma folha de papel dói muito e não sai sangue?". Com auxílio de uma imagem histológica da pele contida na cartilha, a pesquisadora explicou que o corte com a folha de papel geralmente é superficial e acaba lesionando somente a epiderme que é avascular, por isso não sangra, porém, essa camada da pele possui uma grande quantidade de nociceptores (receptores para a dor) que são estimulados no momento da lesão. Para Fonseca e Duso (2018) o ensino de Ciências deve ser motivador, tanto nos anos iniciais como nos anos finais do Ensino Fundamental, mobilizando a curiosidade sobre o que acontece no mundo natural e fazendo uso de ferramentas da linguagem científica. De acordo com a Base Nacional Comum Curricular (BNCC):

\footnotetext{
Ao iniciar o Ensino Fundamental, os alunos possuem vivências, saberes, interesses e curiosidades sobre o mundo natural e tecnológico que devem ser valorizados e mobilizados. Esse deve ser o ponto de partida de atividades que assegurem a construção de conhecimentos sistematizados de Ciências, oferecendo-Ihes elementos para que compreendam desde fenômenos de seu ambiente imediato até temáticas mais amplas (BRASIL, 2018, p. 329).
}

Ao apresentar os personagens da cartilha: Melano e Querato, a pesquisadora explicou que esses representam dois tipos de células encontradas na epiderme o melanócito (produz melanina) e o queratinócito (células de proteção), abordando também a função da melanina como um pigmento responsável pela cor da pele e que confere proteção ao núcleo das células epidérmicas contra a ação dos raios ultravioleta (UV) do sol (JUNQUEIRA \& CARNEIRO, 2017). Após a explanação, alguns alunos do 4으 e 5ㅇa anos da E1 associaram as explicações sobre a melanina à questão do albinismo e perguntaram: "como se chama aquela pessoa que é bem branquinha?", "por que ela é assim?" "essa pessoa corre mais riscos quando fica exposta ao sol?". Foi então explicado que o albinismo é uma doença genética, onde as células do corpo não são capazes de produzir melanina e que atualmente não existe tratamento. Segundo a SBD (2018), essas pessoas apresentam frequentemente, envelhecimento precoce, danos actínicos e câncer de pele ainda muito jovens, especialmente aqueles que moram em regiões quentes e se expõem de forma prolongada e intensa à radiação solar. 
Quando abordado sobre os riscos da exposição excessiva ao sol, vários alunos contaram que seus pais ou avós trabalham na lavoura diariamente e chegam em casa com a "pele vermelha". Entende-se, com esses relatos, que os recursos pedagógicos permitiram aos estudantes associar o conteúdo abordado ao contexto sociocultural dos familiares, conforme relatado por um aluno do 5 ㅇ ano: "Obrigada pelas informações professora, meu pai é agricultor e trabalha o dia inteiro no sol e eu também ajudo ele[sic]." De acordo com Fonseca e Duso (2018), deve existir uma conexão entre o contexto da realidade do estudante e os conteúdos trabalhados, para que o assunto abordado tenha um significado.

Evitar a exposição ao sol das $10 \mathrm{~h}$ às $16 \mathrm{~h}$ representa uma das dicas de cuidado e proteção da pele apresentadas na cartilha. Para facilitar o entendimento dos alunos dos anos iniciais sobre o melhor horário de ficar ao sol, foi explicada a regra da sombra, onde é possível perceber que o risco de ficar ao sol é menor quanto maior o tamanho da sombra da criança em relação à sua altura, de forma que, o sol é mais danoso quanto menor for a sombra (SCHALKA, 2010).

Nos anos finais do Ensino Fundamental, pôde-se perceber certa inibição por parte dos estudantes em fazer questionamentos e participar da discussão da cartilha. No entanto, uma aluna do 8 o ano indagou sobre a possibilidade de desenvolver câncer de pele já que sua mãe e avó materna tiveram. Para responder a indagação, foram destacados os fatores de risco para desenvolvimento do câncer de pele, quais sejam: pele clara, exposição excessiva ao sol, viver em climas quentes e ensolarados, história familiar de câncer de pele e sistema imunológico deprimido (REZENDE et al., 2008; LUZ, 2008; POPIM et al., 2008; ZINK, 2014). Do mesmo modo, alertou-se sobre a importância da prevenção e diagnóstico precoce do câncer de pele (REZENDE et al., 2008; LUZ, 2008).

Outro estudante do 9o ano questionou: "A pessoa de pele negra tem mais melanócitos? Por isso ela produz mais melanina? Ela precisa usar protetor solar e pode desenvolver o câncer de pele?" Com esse questionamento, a pesquisadora aproveitou a ocasião para explicar que tanto na pele branca quanto na pele negra existe aproximadamente a mesma quantidade de melanócitos e as diferenças na coloração da pele são determinadas geneticamente, pela variação na capacidade de produzir maior ou menor quantidade de melanina (JUNQUEIRA; CARNEIRO, 2017). Segundo Wooley-Loyd (2004), provavelmente devido à fotoproteção conferida pela melanina da pele mais pigmentada, os cânceres da pele são menos frequentes em pacientes negros. Mas, apesar do menor risco dessa população, pacientes negros que desenvolvem câncer de pele são confrontados com o aumento da morbidade e mortalidade, as quais são frequentemente resultado de um diagnóstico tardio nesses pacientes.

Ademais, a pesquisadora problematizou o conteúdo exibido pelo recurso pedagógico. Assim, quando apresentado o protetor solar como um ajudante das células da pele ao combate dos raios UV, os alunos foram questionados quanto ao uso regular do protetor solar, bem como, sobre o entendimento do significado da sigla FPS (fator de proteção solar) o qual aparece nos frascos do produto. Praticamente todos os estudantes afirmaram fazer uso do protetor solar, porém, quando explanado sobre a maneira correta de sua aplicação, notou-se a forma inadequada da utilização desse recurso. Nesse sentido, os alunos relataram a aplicação do produto em pequenas quantidades, imediatamente antes de se expor 
ao sol e a não reaplicação durante o decorrer do dia ou após banho de piscina/mar e sudorese intensa.

Com relação ao FPS, alguns estudantes responderam que significava o tempo de ação do protetor, por exemplo, FPS 30 age por trinta minutos, FPS 70 age por setenta minutos. A concepção equivocada a respeito do FPS foi elucidada pela pesquisadora, assim como foram dadas instruções sobre a quantidade adequada de protetor solar a ser utilizada em cada parte do corpo e a necessidade de reaplicar o produto a cada duas horas a fim de garantir a sua eficácia. De acordo com Schalka e Reis (2011, p.511), o FPS é indicado por um número; FPS-15, por exemplo, indica que, usando esse filtro solar de forma adequada, uma pessoa pode ficar exposta ao Sol por um tempo até 15 vezes maior do que poderia ficar sem nenhuma proteção. Ou seja, se uma pessoa começa a desenvolver lesões na pele após ficar 20 minutos exposta ao sol sem protetor solar, poderá ficar 300 minutos exposta ao sol com um protetor de FPS = 15 sem desenvolver nenhuma lesão, pois $20 \times 15$ = 300 (FLOR; DAVOLOS; CORREA, 2007).

Para explicar as características das lesões normais da pele e lesões com sinais sugestivos de tumor de pele do tipo melanoma, foi apresentado aos alunos o folder: $A B C D E$ do câncer de pele. Tal recurso aborda as características semiológicas da lesão de pele a serem observadas para alertar a população leiga sobre a possibilidade de malignidade da lesão, quais sejam: Assimetria, Borda, Cor, Diâmetro e Evolução (SBD, 2018; INCA, 2018). Depois da apresentação do folder, vários alunos dos anos iniciais expressaram contentamento em conhecer tais características, alegando que poderão ajudar familiares e vizinhos, como relatado em algumas falas: "Agora vou poder ajudar minha avó, que tem câncer de pele" (Aluno do 5o ano, E2); "Vou falar pro[sic] meu vizinho que tem uma pinta estranha no rosto" (Aluno do 4ㅇano, E1). Dessa forma, os estudantes podem se colocar em alerta ao saber reconhecer em alguém próximo as manifestações do câncer de pele e orientar a procurar ajuda do médico dermatologista, profissional mais indicado para a confirmação do diagnóstico. Estudos mostram que o melanoma é curável se diagnosticado em estágio inicial (BAKOS et al. 2002; THOMPSON, 2002; TSAO, ATKINS E SOBER, 2004;).

O flyer, com as mesmas informações do folder, foi entregue para os estudantes com o intuito de que estes distribuíssem a seus familiares e conhecidos, disseminando junto à comunidade as informações acerca do conteúdo apresentado, agindo desta forma, como multiplicadores de conceitos científicos. De acordo com Reis (2011) todo conhecimento adquirido na escola deve contribuir para que o educando transforme sua realidade individual e propicie a construção de novas realidades sociais.

A seguir, apresenta-se a análise das respostas obtidas no questionário aplicado aos estudantes quinze dias após a interação com os recursos pedagógicos, no qual se indagou a respeito da importância de terem participado da pesquisa e da possível divulgação dos conceitos apreendidos para outras pessoas.

\section{RESULTADOS E DISCUSSÃO DA QUESTÃO 01 DO QUESTIONÁRIO}

As respostas obtidas para a questão 1: Você achou importante participar dessa pesquisa? Por quê? foram agrupadas em 4 categorias, conforme Figura 2. 
Figura 2 - Categorias de respostas obtidas para a questão: Você achou importante participar dessa pesquisa? Por quê?

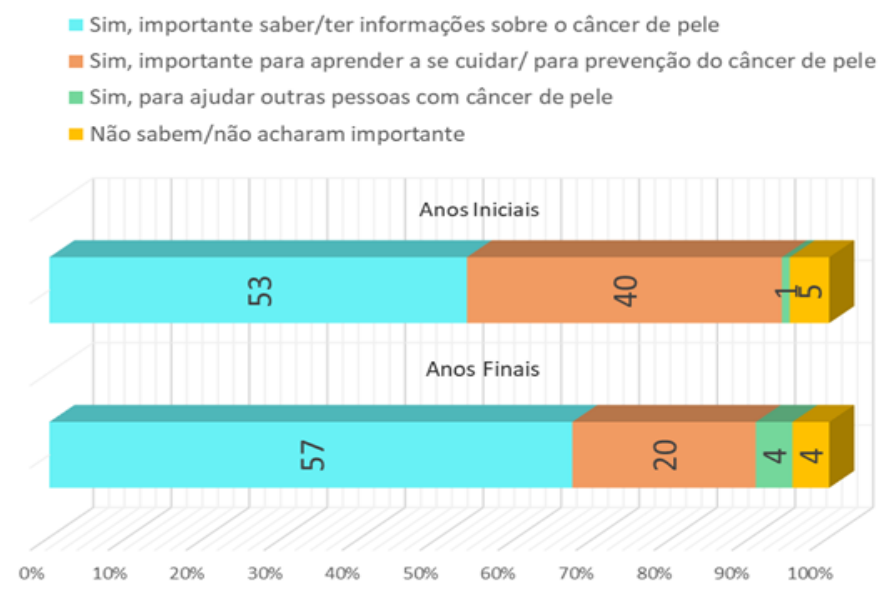

Fonte: Autoria própria (2019). Cada porção da barra apresenta seu n correspondente.

Observou-se que a maior porcentagem de respostas com relação à importância de ter participado da pesquisa concentrou-se, tanto nos anos iniciais quanto nos anos finais, na categoria: Sim, importante saber/ter informações sobre o câncer de pele. Nas justificativas apresentadas pelos estudantes, pode-se constatar que o tema abordado nos recursos pedagógicos foi significativo para suas vidas, visto que aprenderam ou somaram conhecimentos a respeito dessa patologia e os fizerem entender sobre como o câncer de pele se desenvolve, de acordo com o relatado em algumas respostas: Sim, porque eu entendi sobre o câncer de pele (A5-E1, 3ㅇ ano);Eu acho importante participar dessa pesquisa, porque a gente aprende sobre o câncer de pele (A8-E1, 50 ano);Gostei muito porque nos ajuda a pensar no assunto (A4-E2, 6ㅇano);Achei importante, porque é bom saber sobre o câncer de pele, como é, as causas, os riscos de ficar no sol (A12E1, 8 o ano);Sim, porque a gente aprende mais sobre o que pode acontecer se a gente ficar no sol por muito tempo(A9-E2, 8ano);Sim, porque acabamos descobrindo várias coisas sobre a doença e como ela começa (A15-E1, 9ano).

Venturi e Mohr (2011) defendem que a escola deve propiciar aos alunos a construção de conhecimentos e reflexão para que possam dispor de autonomia em suas escolhas e que estas possam ser baseadas em conhecimento científico, caso eles o queiram. Sob essa perspectiva, o ensino de ciências pode contribuir para que os alunos sejam inseridos em uma nova cultura, a cultura científica, que Ihes possibilitará ver e compreender o mundo com maior criticidade e com conhecimentos para discernir, julgar e fazer escolhas conscientes em seu cotidiano, com vistas a uma melhor qualidade de vida. (LORENZETTI; DELIZOICOV, 2001; VIECHENESKI; CARLETTO, 2013).

Nos resultados apresentados para a categoria: Sim, importante para aprender a se cuidar/para prevenção do câncer de pele, os estudantes relataram a importância de conhecer os fatores de risco para o desenvolvimento do câncer de pele e os meios de prevenção da doença, como observado nas seguintes respostas: Gostei de ter participado, porque trás [sic] informações para a pessoa se cuidar (A5-E1, 3 ano); Sim, porque agora eu fiquei sabendo do risco de ficar muito tempo no sol (A7-E2, 4ㅇ ano); Sim, porque a gente aprendeu o que fazer quando vamos para o sol (A1-3E2, 5o ano);Foi importante porque nós podemos aprender a evitar 
o câncer de pele (A2-E1, 5 ano);Sim, porque a gente fica mais atento em relação a exposição ao sol (A7-E1, 8ano);Importante. Por mais que já conheça algumas informações sobre o câncer de pele, tive a oportunidade de entender melhor quais as medidas para preveni-la (A1-E2, 9o ano); Sim, porque daí ficamos sabendo de tudo o necessário pra[sic] não ter câncer de pele (A12-E1, 9ํano).

As respostas dos estudantes demonstram que os recursos pedagógicos contribuíram para a reflexão sobre os riscos da exposição solar em horários onde a radiação UV é intensa e sobre as formas de prevenção do câncer de pele. De acordo com vários autores (EMMONS e COLDITZ, 1999; CRIADO, MELO e OLIVEIRA 2012; CORRÊA e PIRES, 2013; INCA, 2018) a exposição excessiva aos raios ultravioleta do sol durante o período da infância é um fator agravante para o desenvolvimento do câncer de pele na vida adulta. Segundo Silva e Schwantes (2016), a escola precisa dialogar com crianças e adolescentes sobre as questões envolvendo as radiações solares, não para impor ou forçar hábitos, mas para construir junto aos estudantes um diálogo sobre o sol, "sobre as condições de trabalho de seus pais e responsáveis que, muitas vezes, desenvolvem atividades laborais expostos a radiação UV; e sobre os efeitos positivos e negativos envolvendo a temática em questão" (SILVA e SCHWANTES, 2016, p. 4). Os autores ainda ressaltam que esse diálogo pode contribuir em uma mudança de comportamento, "porém essa decisão partirá dos estudantes e será baseada em conhecimentos, interesses, vontade própria e reflexão"(p. 4).

Na categoria: Sim, para ajudar outras pessoas com câncer de pele, os estudantes alegaram que os conhecimentos adquiridos com a pesquisa permitirão alertar e orientar pessoas desprovidas de informações a procurarem ajuda médica ao menor sinal de suspeita do câncer de pele, como declarado em algumas respostas: Sim, porque pode ter pessoas com câncer de pele e eu poderei ajudar. (A3-E1, 5ano); Sim, porque eu quero saber para quando alguém tiver eu saberia o que fazer. (A8-E2, 50 ano); Sim, para saber se alguém da minha família tem câncer de pele. (A1-E2, 4ㅇ ano); Gostei muito, para poder ajudar outras pessoas que não sabem. (A4-E1, 60 ano).

Sasseron e Carvalho (2011) ressaltam que a AC deve estimular os alunos a analisar e avaliar os conceitos científicos apresentados sobre determinado tema, a fim de torná-los capazes de por em prática aquilo que aprenderam, beneficiando a si próprio e aqueles que estão à sua volta. De acordo com os PCN, ao educar para a saúde, de forma contextualizada e sistemática, o professor e a comunidade escolar contribuem de maneira decisiva na formação de cidadãos capazes de atuar em favor da melhoria dos níveis de saúde pessoais e da coletividade (BRASIL, 1996).

Na categoria: Não sabem/ não acharam importante, 4,7\% dos alunos dos anos iniciais responderam não saber qual a importância da pesquisa e nos anos finais, $5,05 \%$ responderam não saber ou não achar importante o tema abordado, como se pode observar nas seguintes respostas: Não achei importante porque sei me cuidar quando estou exposto ao sol (A18-E1, 9o ano); Não, eu não queria participar da pesquisa (A16-E1, 7ำ ano); Não sei. (A15-E1 eA14 - E2, 7으 ano); Não achei importante, mas até que foi legal (A10-E1, 7ํano).

Apesar de não terem achado importante ou de não saberem explicar a real importância de se obter conhecimentos científicos a respeito do câncer de pele, 
por esse ser um assunto associado ao contexto histórico e social no qual o aluno está inserido, as informações que receberam poderão, segundo Libâneo (2010), prover habilidades cognitivas e operativas para a participação na vida social e no que significa o acesso à cultura, ao trabalho, ao progresso e à cidadania.

\section{RESULTADOS E DISCUSSÃO DA QUESTÃO O2 DO QUESTIONÁRIO}

A análise das respostas obtidas na questão 02: Você passou as informações que recebeu sobre como identificar e prevenir (evitar que aconteça) o câncer de pele para mais alguém? Se sua resposta foi sim, para quem passou?, mostrou que $82,35 \%$ dos estudantes dos anos iniciais e $72,72 \%$ dos estudantes dos anos finais divulgaram as informações a respeito do meios de prevenção e identificação do câncer de pele aos familiares, amigos e vizinhos. De acordo com as repostas do questionário, foi possível constatar a importância dos conceitos apresentados nos recursos pedagógicos para o contexto diário dos mesmos, considerando que a maioria dos entrevistados são filhos de produtores rurais, cujo trabalho diário dos familiares abarca exposição contínua ao sol, conforme observado em algumas respostas: Contei para meus familiares que trabalham na fazenda para evitar câncer de pele (A5 - E1, 5 ano);Falei pro meu pai que trabalha em lavouras e fica muito tempo no sol (A2 - E2, 8 ano);Disse para meus pais - principalmente para minha mãe, para ela "chamar mais a atenção do meu pai", que é agricultor (A3 E2, 9o ano);Sim, minha avó entre tios e tias que trabalham no sol (A4 - E1, 9ano).

Essas respostas permitem considerar que os recursos pedagógicos utilizados constituem a base para contribuir de forma significativa ao processo de desenvolvimento da autonomia e da responsabilidade social dos alunos, o que de acordo com a Base Nacional Comum Curricular (BNCC) possibilita que esses alunos tenham um novo olhar sobre o mundo que os cerca, como também façam escolhas e intervenções conscientes e pautadas nos princípios da sustentabilidade e do bem comum (BRASIL, 2018.)

De acordo com Marcondes (2008):

É importante que o aluno reconheça a importância da temática para si próprio e para o grupo social a que pertence. Dessa forma, irá dar uma significação ao seu aprendizado, já possuindo, certamente, conhecimentos com os quais vai analisar as situações que a temática apresenta (MARCONDES, 2008, p.69).

A importância do tema da pesquisa para a comunidade escolar também ficou evidente através das falas das diretoras das escolas, diante das anotações do diário de campo: "É um tema muito relevante, pois a maioria dos alunos são filhos de agricultores e têm a pele clara." (Diretora da E1); "Muitos alunos são filhos de agricultores. Meu marido trabalha todos os dias na lavoura e só passa protetor solar antes de sair de casa porque ele fala que depois que começa a trabalhar fica todo cheio de poeira e não dá mais para repassar o protetor." (Diretora da E2).

Segundo Demo (2005), o ensino de Ciências e Biologia precisa oferecer ao discente um desenvolvimento significativo e coerente com o seu cotidiano, ou seja, o que se aprende na escola deve aparecer na vida. Corroborando com essa afirmação, Clebsch e Venturi (2016, p. 244) ressaltam que, ao trazer temas que fazem parte da realidade dos estudantes para a sala de aula, o professor promove 
a alfabetização cientifica necessária para a inserção crítica e consciente dos indivíduos na sociedade.

\section{RESULTADO E DISCUSSÃO DOS TEXTOS ELABORADOS PELOS ESTUDANTES APÓS OITO MESES DA INTERAÇÃO COM OS RECURSOS PEDAGÓGICOS}

Os textos analisados foram classificados em cinco categorias, cuja frequência e porcentagem são mostradas na figura 3 .

Figura 03 - Categorias obtidas da análise dos textos elaborados pelos estudantes das séries iniciais $(n=85)$ e finais $(n=99)$

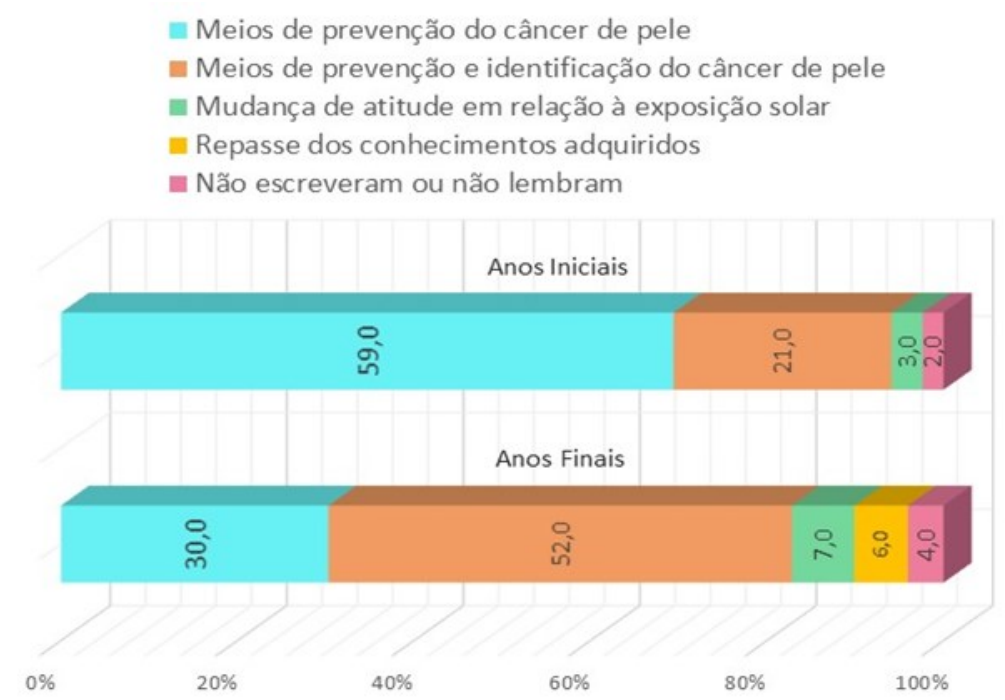

Fonte: Autoria própria (2019). Cada porção da barra apresenta seu n correspondente.

Na categoria Meios de prevenção do câncer de pele, os textos escritos pelos estudantes relataram principalmente a necessidade do uso diário do protetor solar, além do uso de roupas de manga comprida, óculos de sol, chapéu ou boné para auxiliar na proteção da pele. Citaram também que é preciso evitar a exposição solar nos horários em que a radiação ultravioleta é mais intensa (figura 4). Mesmo depois de oito meses da interação com os recursos pedagógicos, percebe-se que as ações realizadas contribuíram para o processo de $A C$ a respeito da prevenção do câncer de pele, promovendo a formação de cidadãos que dominem estes conceitos e sejam capazes de aplicá-los no seu cotidiano. Isso foi verificado pela porcentagem significativa de estudantes que relacionou o uso de medidas fotoprotetoras como uma importante estratégia para reduzir o risco de desenvolver câncer de pele no futuro. 
Figura 4 - Transcrição dos textos da categoria: Meios de prevenção do câncer de pele

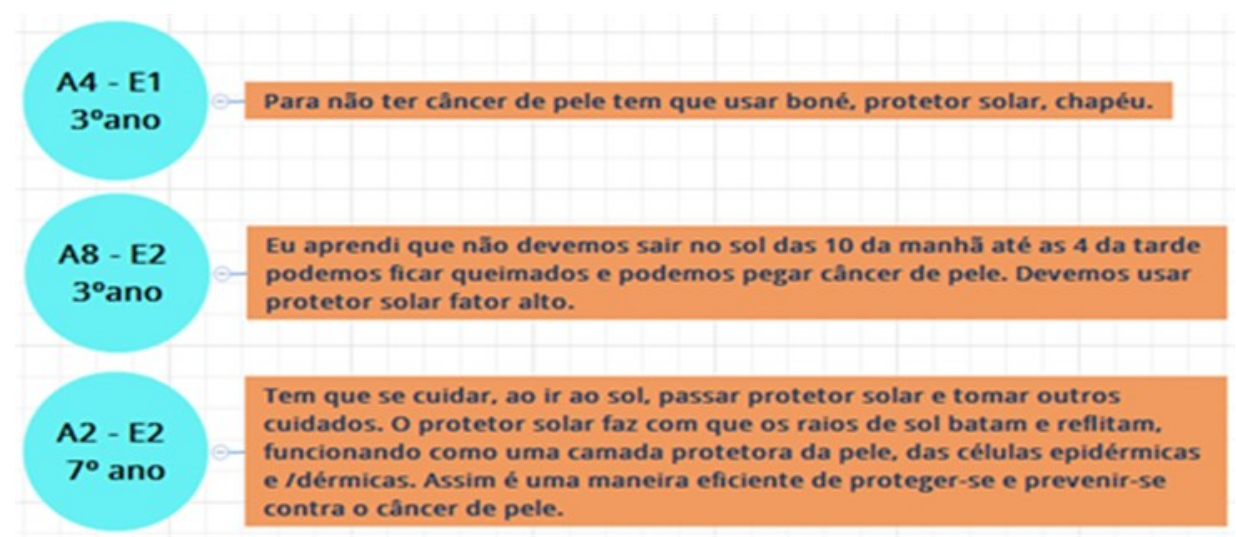

Fonte: Autoria própria (2019). A esquerda está identificado Aluno, Escola e Ano.

Na categoria Meios de prevenção e Identificação do câncer de pele, os textos abrangeram tanto as formas de prevenção quanto a semiologia. Os estudantes expuseram o uso de protetor solar, vestimentas adequadas, horário de exposição ao sol e que devemos ficar atentos às características das "pintas da pele" - quanto à forma, contorno, cor, tamanho e evolução (figura 5). Essas características foram apresentadas aos estudantes através do folder ABCDE do câncer de pele. Além disso, muitos textos falaram da necessidade de procurar ajuda de um médico dermatologista ao observar "pintas estranhas" no corpo.

De acordo com a BNCC, durante o Ensino Fundamental a área de Ciências da Natureza tem um compromisso com o desenvolvimento do letramento científico, que envolve não só a capacidade de compreender e interpretar o mundo (natural, social e tecnológico), mas, também, de transformá-lo com base nos aportes teóricos e processuais das ciências (BRASIL, 2018). Portanto, os conceitos e conhecimentos construídos na escola são ingredientes para o exercício da reflexão que, combinados com a aprendizagem, vão capacitar o indivíduo à autonomia consciente de seus atos (MULINARI, 2018).

Figura 5 - Transcrição dos textos da categoria: Meios de prevenção e Identificação do câncer de pele

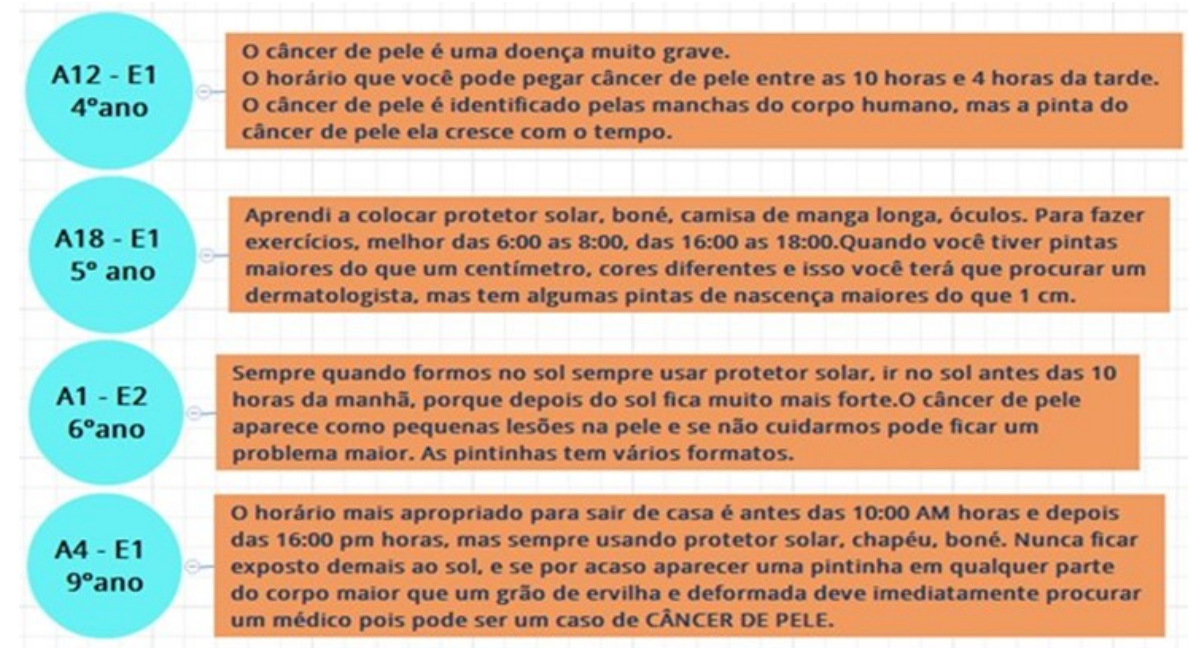

Fonte: Autoria própria (2019). A esquerda está identificado Aluno, Escola e Ano. 
Na categoria 3 Mudança de atitude em relação à exposição solar, foi relatado mudança de atitudes depois da participação na pesquisa, enfatizando os cuidados com o uso do protetor solar, vestimentas adequadas e ainda com os horários apropriados para se expor ao sol. Nos textos, os estudantes deixaram transparecer a sua conscientização em relação a mudança de comportamento diante da exposição solar (figura 6).

Conforme estes textos, percebe-se que os recursos pedagógicos auxiliaram os estudantes no entendimento dos fatores que levam ao desenvolvimento do câncer de pele, viabilizando a conscientização de se fazer uso de medidas fotoprotetoras para prevenção dessa patologia. De acordo com Mohr e Venturi (2013), a autonomia frente ao conhecimento permite ao indivíduo liberar-se de receitas prontas, regras, ordens e das prescrições ditadas por outrem sobre o que é adequado ou saudável para manter ou recuperar a saúde. Sasseron e Carvalho (2011) asseguram que a prática da AC para o ensino de ciências implica no planejamento do ensino capaz de oferecer aos estudantes condições de entenderem as ciências e como elas se relacionam com nossas vidas, influenciando na sociedade e no ambiente, além de possibilitar a tomada de decisões e a explicitação de ponto de vista.

Figura 6 - Textos da categoria: Mudança de atitude em relação à exposição solar

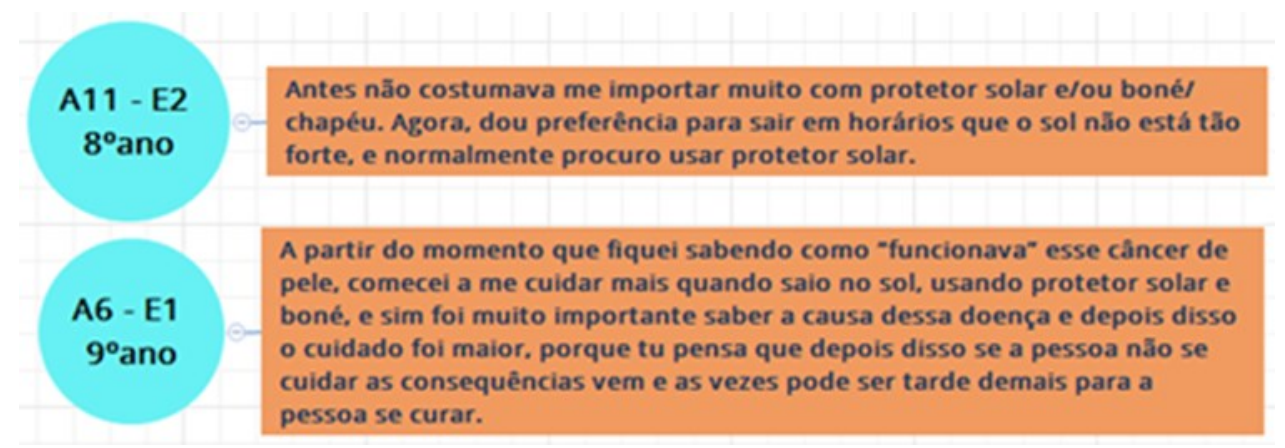

Fonte: Autoria própria (2019). A esquerda está identificado Aluno, Escola e Ano.

$\mathrm{Na}$ categoria Repasse dos conhecimentos adquiridos, os alunos relataram o compartilhamento das informações a respeito dos fatores que desencadeiam o câncer de pele e de como preveni-lo, alcançando principalmente, familiares que têm ou já tiveram a doença (Figura 7).

Figura 7 - Transcrições dos textos da categoria: Repasse dos conhecimentos adquiridos

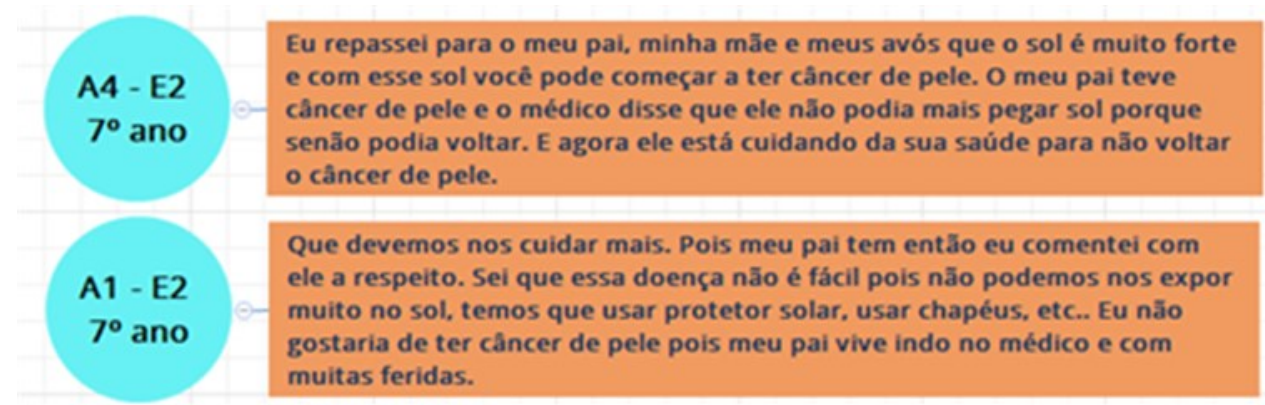

Fonte: Autoria própria (2019). A esquerda está identificado Aluno, Escola e Ano. 
O conteúdo apresentado pelos recursos pedagógicos ganhou significado para os estudantes por ser condizente à realidade social e cultural dos mesmos e da comunidade escolar. Assim, os alunos puderam potencializar esses conhecimentos atuando como agentes multiplicadores de informação, visando a melhoria da sua qualidade de vida e dos que estão à sua volta. Os PCN apontam que devem ser contempladas aprendizagens que permitam efetivar o princípio de participação e o exercício das atitudes e dos conhecimentos adquiridos. A participação é um princípio da democracia que necessita ser trabalhado, pois se aprende a participar participando, sendo ainda importante considerar que a mesma deve ser dimensionada a partir dos limites de possibilidade dos alunos e da complexidade das situações (BRASIL, 1997).

$\mathrm{Na}$ categoria Não escreveram ou não lembram, cinco estudantes não responderam e somente um escreveu: "... faz tempo que tive essa palestra." (A2 E2, 9ano). Vários podem ter sido os motivos, tais como: esquecimento do assunto abordado, indiferença com a atividade proposta, não apreensão dos conceitos ou dificuldade de se expressar através da escrita (sendo esta relatada pelos professores dos anos iniciais durante a execução da atividade).

Passados oito meses da realização da oficina, a maioria dos estudantes expressou em seus textos conceitos enfatizados nos recursos pedagógicos a respeito das causas, prevenção e diagnóstico do câncer de pele, assim como, relataram o repasse das informações recebidas para familiares e vizinhos. Com isso, puderam-se identificar nos textos analisados diferentes indicadores de AC (figura 8) propostos por Sasseron e Carvalho (2008). Os indícios demonstrados pela participação dos alunos em sala ao realizarem as atividades propostas, denotam situações de aprendizagem em Ciências e constituem os indicadores de alfabetização científica. Estes podem ser evidenciados pelo desenvolvimento de habilidades para: seriação, organização e classificação de informações, raciocínio lógico e proporcional, levantamento e teste de hipóteses, justificativa, previsão e explicação.

Figura 08 - Relação entre as categorias do texto e os indicadores de AC

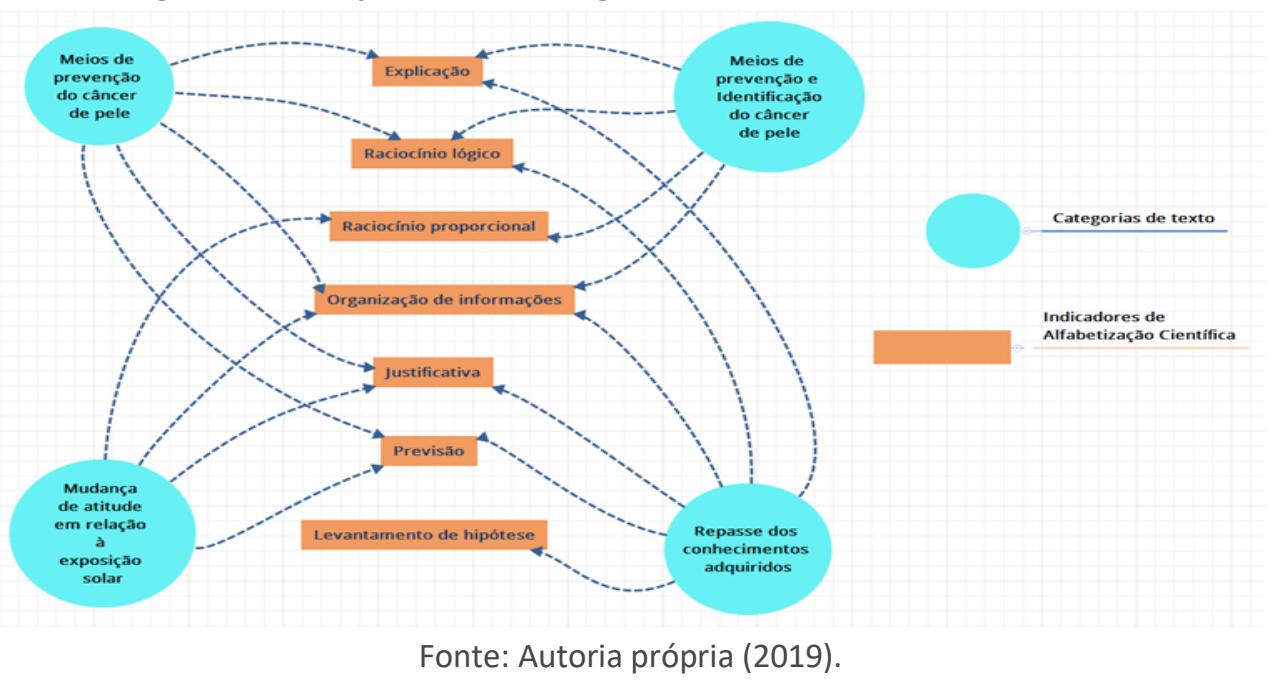

Como observável na figura 08 , o indicador da AC mais evidente nos textos foi a organização de informações. Segundo Sasseron e Carvalho (2008) esse indicador marca o início do processo da AC, pois demonstra que o estudante encontrou uma 
forma de trabalhar as informações e percebê-las com mais clareza, daí estabelecendo novos conhecimentos.

Na transcrição: "Para não ter câncer de pele tem que usar boné, protetor solar, chapéu.", evidencia-se o raciocínio lógico, que proporciona coesão e coerência aos argumentos apresentados. Enquanto na frase: "O horário que você pode pegar câncer de pele entre as 10 horas e 4 horas da tarde.", o aluno demonstra o raciocínio proporcional como forma de entender e explicar as relações entre exposição solar e desenvolvimento do câncer de pele. Sendo assim, o uso de indicadores é importante não só por evidenciar que os alunos encaminham-se para a Alfabetização Científica, mas também porque representam habilidades importantes de serem trabalhadas nas aulas de qualquer disciplina (SASSERON e CARVALHO, 2008).

Além disso, a figura 08 indica que ocorreram diversas vias de correlação entre as categorias e os indicadores da alfabetização científica, podendo-se evidenciar que todos os alunos participaram do processo de $A C$, ainda que em diferentes graus. De acordo com Sasseron (2015), um indivíduo alfabetizado cientificamente pode apresentar mais facilidade de interagir com o seu meio, com as diferentes culturas, ver o mundo de forma mais completa percebendo e compreendendo melhor suas mudanças e acontecimentos. Segundo Sasseron e Carvalho (2011), essa interação do sujeito com o meio, de forma a interferir nas ações cotidianas assertivamente se dá por ações conscientes mediadas pelos conhecimentos científicos.

\section{CONSIDERAÇÕES FINAIS}

A partir das análises e discussões dos resultados do presente estudo é possível inferir que as ferramentas pedagógicas de caráter lúdico-interativo abordando o tema câncer de pele favoreceram a promoção da AC de alunos dos anos iniciais e finais do Ensino Fundamental de duas escolas públicas do campo, localizadas no município de Silveira Martins/RS e do distrito de Vale Vêneto/RS. Fundamentando e ampliando a construção do conhecimento acerca da relação entre o desenvolvimento do câncer de pele e a exposição excessiva aos raios ultravioletas do sol. Contribuíram também com o contexto da comunidade escolar, uma vez que as escolas estão localizadas em área rural e a atividade econômica dessa comunidade está voltada para agricultura. Ademais, os estudantes poderão participar de forma responsável na multiplicação dos conhecimentos adquiridos em favor da melhoria da sua qualidade de vida e dos que estão à sua volta.

O folder $A B C D E$ do câncer de pele e o flyer despertaram o interesse dos alunos em relação ao tema proposto, motivando-os ao questionamento e compartilhamento de suas vivências, o que contribuiu para a construção do conhecimento de forma participativa, agradável e prazerosa. Logo, permitiram aos estudantes a organização, apropriação e domínio de conceitos científicos básicos para se identificar as características de lesões de pele sugestivas de malignidade, tornando-os capazes de aplicá-los no seu cotidiano e em favor da coletividade.

Estes recursos pedagógicos lograram o desenvolvimento de habilidades cognitivas como raciocínio lógico e proporcional, justificativa e teste de hipóteses, previsão e explicação, reforçando o senso crítico frente aos fatores que levam ao 
desenvolvimento do câncer de pele. Dessa forma, ao construir sentido e significado, despertou a conscientização dos estudantes frente aos riscos da exposição solar em horários de maior intensidade de radiação ultravioleta e a importância do uso regular do protetor solar e outros meios físicos de fotoproteção. A partir da reflexão crítica, possibilitou o posicionamento perante a prevenção e diagnóstico precoce do câncer de pele, habilitando o aluno para agir e escolher com autonomia, fundamentado por conhecimentos científicos significativos.

Desse modo, espera-se que esse estudo possa contribuir com o ensino de Ciências na criação de estratégias educativas que favoreçam a construção de conhecimentos sobre o câncer de pele, que desenvolvam junto aos estudantes a criticidade e a formação de cidadãos autônomos, capazes de relacionarem o que aprendem à sua vida diária, intervindo no mundo que estão inseridos. 


\title{
Contributions of pedagogical resources on skin cancer for Science literacy in Elementary School
}

\begin{abstract}
According to the National Cancer Institute (INCA, 2018), children are exposed to the sun three times more than adults annually. Research indicates that childhood is a particularly vulnerable phase to the sun's harmful effects. Cumulative and excessive exposure to it during the first 10 to 20 years of life greatly increases the risk of skin cancer in adulthood or old age. Therefore, this study evaluated assessed the contributions of the use of ludicinteractive pedagogical resources comprising the skin cancer issue for the promotion of Scientific Literacy of students from the 3rd to the 9th of Elementary School from two rural public schools. The research applied a qualitative multiple cases study methodology. A workshop was conducted, in which the students received a paradidactic booklet, a folder and a flyer approaching the skin cancer issue. The students interacted with the material and could take it home. The field notes, the questionnaires and a text written by the students about the discussed issue were used as the data collection instrument. The methodology employed for processing the data was based on descriptive statistics and content analysis. Results evidenced that the pedagogical resources allowed the organization, appropriation and apprehension of scientific concepts towards the causes, prevention and identification of skin cancer. It was also possible to highlight several indicators of scientific literacy, as well as the construction of sense and meaning, enabling the student to act and choose with autonomy, based on scientific knowledge. Thus, it is expected that students become critical agents and autonomous citizens, able to connect school learning and daily life, intervening in the environment in which they are inserted.

KEYWORDS: Scientific literacy. Elementary School. Pedagogical resources. Skin cancer.
\end{abstract}




\section{REFERÊNCIAS}

AMADOR, N. L.; TRINDADE, R. J.; GOMES, P. W. P.; RAMOS, E. Z.; SOUZA, R. F. Estratégia didática: utilizando a modelagem para facilitar o ensino $\mathrm{e}$ aprendizagem da temática Terra e Universo. ACTIO, Curitiba, v. 3, n. 3, p. 26-42, set./dez. 2018.

BAKOS, L.; WAGNER, M.; BAKOS, R. M.; LEITE, C. S.; SPERHACKE, C.S.; DZEKANIAK, K. S.; GLEISNER, A. L. Sunburn, sunscreens and phenothypes: some risk factors for cutaneous melanoma in southern Brazil. International Journal of Dermatology. $v$. 4, p. 557-62, 2002.

BARDIN, L. Análise de conteúdo. São Paulo: Edições 70, 2016.

BRASIL. Ministério da Educação e do Desporto. Secretaria da Educação do Ensino Fundamental. Parâmetros Curriculares Nacionais: Ensino Fundamental. Brasília: MEC/SEF, 1996.

BRASIL. Ministério da Educação. Secretaria de Educação Fundamental. Parâmetros Curriculares Nacionais: apresentação dos temas transversais, Ética. Brasília, 1997.

BRASIL. Ministério da Educação. Base Nacional Comum Curricular: Ensino Fundamental, v. 3, 2018.

CLEBSCH, A. B.; VENTURI, T. Ensino do Câncer de Pele na Escola Básica utilizando material de Divulgação Científica. Revista de Investigación, n. 88, v. 40, p. 229 247, Mayo-Agosto, 2016.

CORRÊA, M. P.; PIRES, L. C. M. Doses of erythemal ultravioleta radiation observed in Brazil. International Journal of Dermatology, v. 52, n. 8, p. 966-73, May 2013.

COSTA, G. R.; BATISTA, K. M. A Importância das Atividades Práticas nas Aulas de Ciências nas Turmas do Ensino Fundamental. Revista de Educação do Vale do São Francisco, v. 7, n. 12, 2017, p. 06-20.

CRIADO, P. R.; MELO, J. N.; OLIVEIRA, Z. N. P. Fotoproteção tópica na infância e na adolescência. Jornal de Pediatria, v. 88, n. 3, p. 203- 210, 2012.

DEMO, P. Educar pela pesquisa. 7. ed. Campinas: Autores Associados, 2005.

DELIZOICOV, D.; LORENZETTI, L. Alfabetização científica no contexto das séries iniciais. Ensaio - Pesquisa em Educação em Ciências, v. 3, n. 1, p. 37-50, 2001.

DIEPGEN, T. L.; MAHLER V. The epidemiology of skin cancer. British Journal of Dermatology, v. 146, n. 61, p. 1-6, May, 2002.

EMMONS, K.; COLDITZ, G. Preventing excess sun exposure: it is time for a national policy. Journal of the National Cancer Institute, v. 91, n. 15, p. 12691270, 1999. 
FERREIRA, F.; NASCIMENTO, L. F. C.; ROTTA, O. Fatores de risco para câncer da pele não melanoma em Taubaté, SP: um estudo caso-controle. Revista da Associação Medica Brasileira, São Paulo, v. 57, n. 4, p. 431-437, jul./ago. 2011.

FLOR, J.; DAVOLOS, M. R.; CORREA, M. A. Protetores solares. Química Nova, São Paulo, v. 30, n.1, p. 153-158, jan./feb. 2007.

FONSECA, E. M.; DUSO, L. Reflexões no ensino de ciências: elaboração e análise de materiais didáticos. REPPE: Revista do Programa de Pós-Graduação em Ensino - Universidade Estadual do Norte do Paraná Cornélio Procópio, v. 2, n. 1, p. 23-44, 2018.

FREIRE, Paulo. Pedagogia do Oprimido. 17. ed. São Paulo: Paz e Terra, 1987.

INSTITUTO NACIONAL DE CÂNCER JOSÉ ALENCAR GOMES DA SILVA/ MINISTÉRIO DA SAÚDE - INCA, Estimativa 2018. INCA, 2018. Disponível em: https://www.inca.gov.br/tipos-de-cancer/cancer-de-pele-nao-melanoma. Acesso em: 09 set. 2018.

JUNQUEIRA, L. C.; CARNEIRO,J. Histologia Básica. 13. ed. Rio de Janeiro: Guanabara Koogan, 2017.

LIBÂNEO, J. C. Didática e prática histórico-social: uma introdução aos fundamentos do trabalho docente. In: LIBÂNEO, J. C. Democratização da escola pública. São Paulo: Cortez Editora, 2010.

LORENZETTI, L.; DELIZOICOV, D. Alfabetização científica no contexto das séries inicias. Ensaio - Pesquisa em Educação em Ciências, v. 3, n. 1, p. 45-61, jan- jun. 2001.

LUZ, F. B. Cânceres da pele não-melanoma. In: SANTOS, C. E. R.; MELLO, E. L. R. (Org.) Manual de Cirurgia Oncológica. 2. ed., São Paulo: Tecmedd, 2008. cap. 44, p. 817-832.

MARCONDES, M. E. R. Proposições Metodológicas para o ensino de Química: Oficinas Temáticas para a aprendizagem da ciência e o desenvolvimento da cidadania. Rev. Em Extensão, Uberlândia, v. 7, p. 67-77, 2008. Disponível em: http://www.seer.ufu.br/index.php/revextensao/article/viewFile/20391/10861. Acesso em: 01 mar. 2017.

MASSARA, C. L.; SCHOLTE, R. G. C.; ENK, M. J. A Utilização do Lúdico na Transmissão de Informação e Conhecimento Sobre Esquistossomose. In: XI SIMPÓSIO INTERNACIONAL SOBRE ESQUISTOSSOMOSE, 2008, Salvador. Anais [...]. Salvador/BA, 2008.

MINAYO, M. C. S. O Desafio do Conhecimento - Pesquisa Qualitativa em Saúde. 10. ed. Editora Hucitec, São Paulo, 2007.

MULINARI, Guilherme. O papel dos professores e profissionais de saúde no Programa Saúde na Escola: uma análise dos documentos de referência a partir da Educação em Saúde Florianópolis, SC. 2018. 105 f. Dissertação (Mestrado em 
Educação Científica e Tecnológica) - Programa de Pós-Graduação em Educação Científica e Tecnológica - Universidade Federal de Santa Catarina, Florianópolis, 2018. Acesso em: 24 de maio de 2019.

OLIVEIRA, C. M. A. Do discurso oral ao texto escrito nas aulas de ciências.2009. 249 f. Tese (Doutorado em Educação), Faculdade de Educação da Universidade de Sâo Paulo, São Paulo, 2009. Acesso em: 24 mai. 2019.

PEREIRA, C. A. A importância da atuação do médico do trabalho na prevenção do câncer de pele ocupacional. Revista Brasileira de Medicina do Trabalho. v. 15, n. 1, p. 73-9, 2017.

POPIM, R. C.; CORRENTE, J. E.; MARINO, J. A. G.; SOUZA, C. A. Câncer de pele: uso de medidas preventivas e perfil demográfico de um grupo de risco na cidade de Botucatu. Ciência \& Saúde Coletiva, v.13, n. 4, p.1331-1336, 2008.

REIS, E. Estatística descritiva. ed. 4. Lisboa: Silabo, 1998.

REIS, T. Educação e cidadania: a batalha de uma Educação comprometida. Rio de Janeiro: Wak, 2011.

REZENDE, J. F. N.; ACETTA, A. C.; MENDES, G. L. Q.; ARAÚJO, M. S. Melanoma. In: SANTOS, C. E. R.; MELLO, E. L. R. (Org.) Manual de Cirurgia Oncológica - 2a ed., São Paulo: Tecmedd, 2008. cap. 43, p. 783-816.

SALLA, L. F. Alfabetização Científica em Ciências Morfológicas para a Promoção da Saúde. In: XXX JORNADA ACADÊMICA INTEGRADA (JAI), 2015, Santa Maria/RS. Jornada Acadêmica Integrada: Compilação de artigos de 2015. Santa Maria, Universidade Federal de Santa Maria, 2018.

SASSERON, L. H.; CARVALHO, A. M. P. Alfabetização científica: uma revisão bibliográfica. Investigações em Ensino de Ciências, Porto Alegre, v. 16, n. 1, p. 59-77, 2011.

SASSERON, L. H.. Alfabetização científica, ensino por investigação e argumentação: relações entre ciências da natureza e escola. Revista Ensaio, Belo Horizonte, v. 17, n. especial, p. 49-67, novembro, 2015.

SCHALKA, S. Fotoproteção na infância. In: I Painel Latino-Americano: Cuidados com a pele infantil. São Paulo, 2010. Disponível em: http://sobende.org.br/pdf/painel-JJ-Fasciculo-4.pdf. Acesso em: 22 out. 2018.

SCHALKA, S.; REIS, V. M. S. Fator de proteção solar: significado e controvérsias. Anais Brasileiros de Dermatologia, Rio de Janeiro, v. 86, n. 3, 507-515, 2011.

SILVA, P. F. K.; SCHWANTES, L. Radiações Solares: a importância da temática interdisciplinar no currículo escolar. In: XV SEMINÁRIO INTERNACIONAL DE EDUCAÇÃO. Educação e Interdisciplinaridade: Percursos teóricos e metodológicos. 2016. Universidade Feevale, Novo Hamburgo/RS, 2016. 
SOCIEDADE BRASILEIRA DE DERMATOLOGIA (SBD). Como prevenir câncer de pele. Rio de Janeiro, 2018. Disponível em:

http://www.sbd.org.br/informacoes/sobre-o-cancer-da-pele/como-prevenirocancer-da-pele/. Acesso em: 08 out. 2018.

SOCIEDADE BRASILEIRA DE DERMATOLOGIA (SBD). Albinismo. Rio de Janeiro, 2018. Disponível em: https://www.sbd.org.br/dermatologia/pele/doencas-eproblemas/albinismo/24/. Acesso em: 08 out. 2018.

THOMPSON, J. The revised american joint committee on cancer staging system for melanoma. Seminars in Oncology, v. 29, n. 4, p. 361-369, August 2002.

TSAO, H.; ATKINS, M.; SOBER, A. Management of cutaneous melanoma. The New England Journal of Medicine, v. 351, p. 998-1012, September, 2004.

VENTURI, T.; MOHR, A. Análise da Educação em Saúde em publicações da área da Educação em Ciências. In: VIII ENCONTRO DE PESQUISA EM EDUCAÇÃO E I CONGRESSO IBEROAMERICANO DE IVESTIGAÇÃO E ENSINO DE CIÊNCIAS, Campinas, 2011. Anais [...]. Campinas, UNICAMP, SP, 2011. Disponível: http://www.nutes.ufrj.br/abrapec/viiienpec/resumos/R0617-1.pdf. Acesso em: 08 out. 2018.

VIECHENESKI, J. P.; CARLETTO, M. R. Por que e para quê ensinar ciências para crianças. Revista Brasileira de Ensino de Ciência e Tecnologia, v. 6, n. 2, p. 213228, mai-ago.2013.

WOOLEY-LOYD, H. Skin Cancer in African-Americans. Skin \& Aging Newsletters, v. 12, n. 4, April 2004. Disponível em: http://www.skinandaging.com/article/2547. Acesso em: 10 out. 2018.

YIN. R. K. Estudo de caso: planejamento e métodos. 3 ed., Porto Alegre: Bookman, 2005.

ZINK, B. S. Câncer de pele: a importância do seu diagnóstico, tratamento e prevenção. Revista HUPE, Rio de Janeiro, v. 13, supl. 1, p. 76-83, ago. 2014.

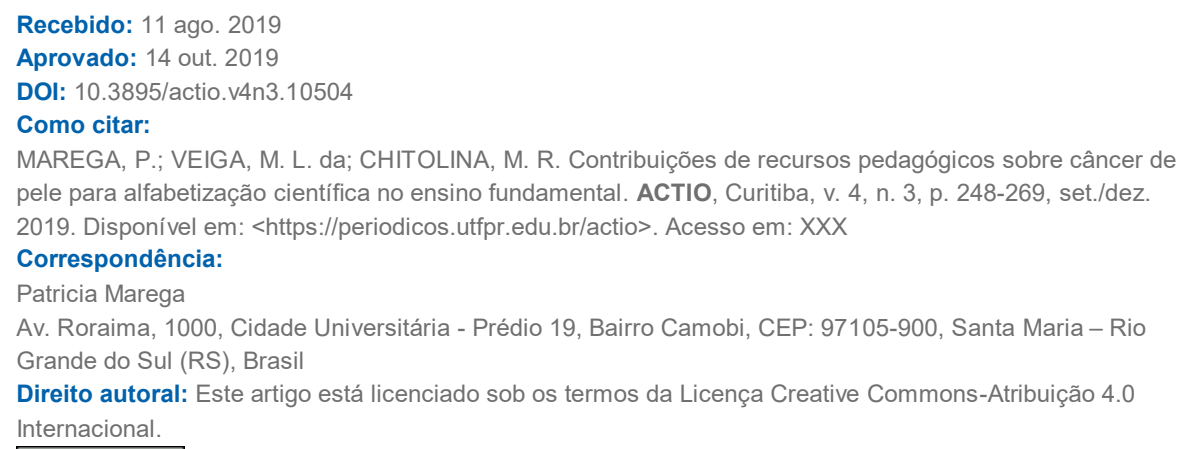

